\title{
A STUDY ON IMPROVEMENT OF THE DEFENSE LOGISTICS INTEGRATED INFORMATION SYSTEM USING THE TECHNOLOGICAL ACCEPTANCE MODEL (TAM)
}

\author{
Eun-Seok Choi ${ }^{1}$ and Myoung-jin Choi ${ }^{2 *}$ \\ ${ }^{1}$ ROK Joint Chiefs of Staff. Republic of Korea \\ ${ }^{2}$ Dept. of Defense Science Technology, Howon University. Republic of Korea \\ 1eschoi317@naver.com. 2officesky@howon.ac.kr
}

\begin{abstract}
The military should efficiently manage peacetime strength and operate military power to achieve victory in a war. Also, it should strive to enhance its readiness with the operation of many personnel, equipment, facilities, etc. However, as a result of increasing difficulty in investing in defense due to citizens' growing request for economic development and welfare, already established information systems should be actively utilized for efficient defense resource management. This study examines the impact of military DELIIS use factors and suggests options to promote the sustainable intent of use of the system. In this regard, the paper sets up a hypothesis on the sustainable intent of use centering on users from military organizations, and conducted surveys on a random sample of logistics action-level personnel in the lowest level of echelons. The results show that the functional quality was the lowest out of all subfactors in an equipment maintenance system including operating system quality, functional quality, content quality, network quality, and service quality. Also, perceived ease (PE) had a medium effect in a relationship with perceived usefulness (PU), and PU had a medium effect in a relationship with PE and sustainable intent of use. Thus, for an equipment maintenance information system (EMIS), it is shown that the swift nature of the system network and improvement of factors considering the user's convenience are important factors, and sustainable use factors include the system's superiority and possibility of wide use.
\end{abstract}

\section{Keywords - DELIIS, TAM, Army, Information System, Equipment Maintenance}

\section{INTRODUCTION}

The army ensures informationalized / scientific logistics support conditions by developing munitions information systems, materiel information systems, facility information systems, transportation information systems, and DELIIS. However, it is crucial that users actually utilize these platforms for the active use and functional working of logistics information systems. DELIIS was fielded in 2009 for efficient maintenance management and repair parts management, but its use is difficult. The Logistics Command organized educational specialists to go around the country to educate and rectify the errors of users, and operate TFs, exerting much effort. It was identified that relatively inexperienced and new users had difficulty using DELLIS. Most users thought of DELIIS as an extremely complicated information system, with low access and a poor

Received: May 7, 2019

Reviewed: August 19, 2019

Accepted: August 28, 2019

* Corresponding Author 
manual. Information technology centering on digital fusion technology has had a significant impact on industries, and academic research on this is required. The shift in the paradigm in the fusion environment brought about a fundamental change in logistics support affairs, and has had a great influence on information efficiency. users' care and convenience in relation to relevant technological development.

The study analyzes requests from logistics personnel on DELIIS, and proposes strategic factors that enable easier and more convenient use, and methods to help logistics personnel with the basic framework of the technological acceptance model (TAM).

\section{RELATED STUDIES}

\subsection{DELIIS}

DELIIS enables equipment status management by registering as an asset and fielding combat equipment and maintenance equipment. Equipment operation based on base documents such as equipment operation certification maintenance order, artillery record, maintenance data, repair parts, billing of parts, supply data are real-time processed. The data is stored and managed in LOGCOM integrated server and enhances credibility of logistics affairs through unified data use of all forces. Also, echelon-by0echelon input of data including budget, requirement, supply, and procurement, and maintenance, synchronization with logistics internal/external systems including CIMMS, WMS, IETM enables efficient equipment maintenance affairs 21,000 users are registered in DELIIS, role of the registered can be divided basic data input and logistics personnel who utilized the stored data. Those who provides input include field units, maintenance units (2-4), supply facilities (1/2/3/ Supply Group), LOGCOM item personnel, and repair parts and maintenance personnel. Users include logisticians from divisions, Corps, Army HQ, GOC, LOFCOM, LSCOM, DAPA, MND and ADD. DELIIS is operated in five groups through an equipment maintenance portal.

\subsection{TECHNOLOGY ACCEPTANCE MODEL}

Whenever a new technology emerges, scholars study factors that affect the reception of the technology. The most frequently cited model is the TAM suggested by Davis [5], which states that perceived ease (PE) and perceived usefulness (PU) influence users' intent and attitude of actions. Since its introduction there have been a number of followup studies in various areas. The model is not only simple but theoretically solid, and can be easily expanded and adjusted to address the diversity of technology reception phenomena. The three main existing theories [16] that verify the process of information technology reception by users are the theory of reasoned action (TRA), theory of planned behavior (TPB), and technology acceptance model (TAM). According to a previous study [18][7], these theories can be roughly distinguished into three areas: first is TRA theory; second is TPB with an added factor of Perceived Behavioral Control (PBC) that expands upon TRA; and third is the TAM, which incorporates new belief variables called perceived usefulness and perceived ease of use by Davis [5] based on the TRA. The three theories are considered to have expanded with a focus on intent and attitude of actions of a user's information technology. The TRA's and TPB's influence on action intent is very simple and abstract and is limited for measuring information technology reception. Accordingly, in order to explain the determining factors of reception and inject theoretical legitimacy, the TAM was suggested by specifying and conceptualizing attitudedetermining factors on TRA actions into PE and PU.

The TAM suggested by Davis can be seen as a model that extends information technology use from the relationship between actions suggested by the TRA and intention to act. In other words, it is a model that can explain information technology users' actions by using basic variables put forward by previous studies and the TRA. 
The TAM and TRA both assume that the use of technology is determined by intention to act. However, the TAM and TRA are different in that with the TAM PU determines, and with the TRA attitude toward use of technology determines. Also, subjective rules were excluded from the TAM due to uncertainty of measurement. Davis, Bagozzi and Warshaw [5] found that early ease along with PU has a direct influence on intention to act, and building on their studies, others [12] omitted attitude when studying the TAM. The TAM has a background of action theory planned with the TRA, and is a special case of the TRA based on socio-psychology.

Because the two theories can be applied well to use actions of information technology, they are used for various research models such as understanding a process or explaining whether a new technology is accepted. The TAM was first proposed by Davis [4], and overcame actual measurement limitations of information technology acceptance that arose from the TPB's and TRA's simplistic and abstract nature. The core concept is shown in Figure 1.

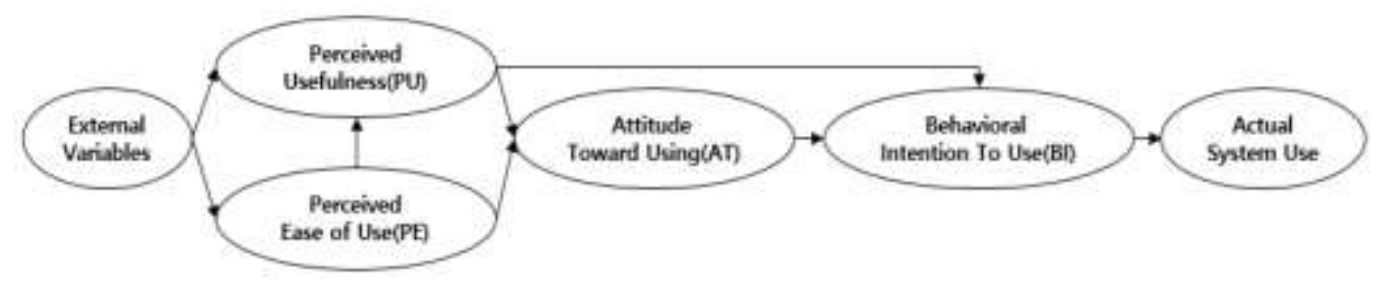

Fig. 1 Technology Acceptance Model

\section{MODELING TO IMPROVE EQUIPMENT MAINTENANCE INFORMATION SYSTEM}

\subsection{MODEL AND HYPOTHESES}

This research analyzed options to enhance the sustainable use intent of the equipment maintenance information system based on the TAM while accounting for realistic problems. The selected subjects include the lowest units of the army, logistics actionlevel personnel, and the model in Figure 2 was set up to verify the structural relationship between PE, PU and sustainable intent of use consisting of user requirements of OS, network, content and service quality.

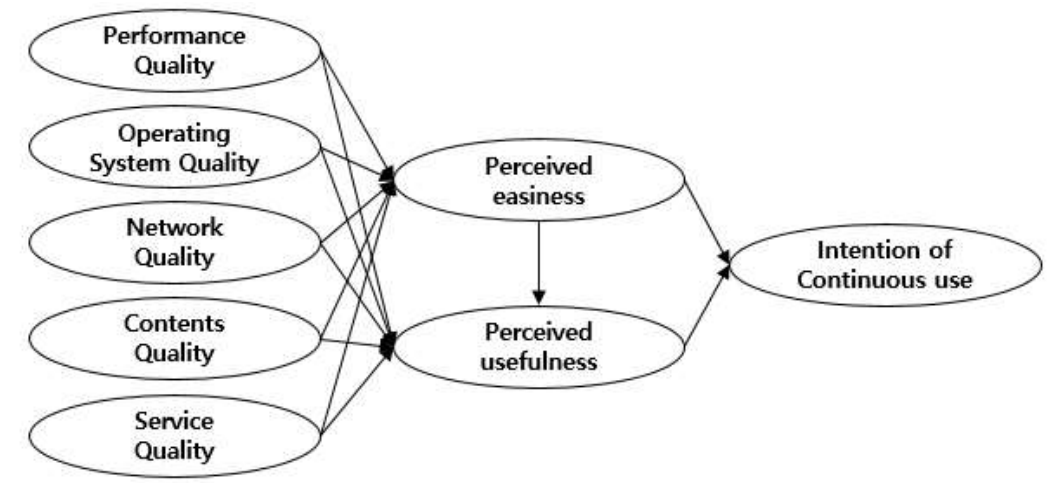

Fig. 2 Model to Improve Equipment Maintenance Information System 
- H1. The equipment maintenance system (functional quality, OS quality, network quality, content quality, service quality) has a meaningful impact on the PE of the equipment maintenance information system.

- H2. The equipment maintenance system (functional quality, OS quality, network quality, content quality, service quality) has a meaningful impact on the PU of the equipment maintenance information system.

- H3. The equipment maintenance information system's PE has a meaningful impact on the equipment maintenance information system's PU.

- H4. The equipment maintenance information system's PE has a meaningful impact on the sustainable intent of use of the equipment maintenance information system

- H5. The equipment maintenance information system's PU has a meaningful impact on the sustainable intent of use of the equipment maintenance information system.

- H6. The PE between the equipment maintenance information system's PU and equipment maintenance system (functional quality, OS quality, network quality, content quality, service quality) has a connecting effect.

- H7. The PU between the equipment maintenance information system's PE and the sustainable intent of use of the equipment maintenance information system has a connecting effect.

\subsection{DATA COLLECTION AND MEASUREMENT TOOLS}

Survey items were modified and supplemented for the purpose of this research based on existing studies to verify hypotheses. Surveys were conducted randomly among lower army units and logistics action officers from 5 to 23 March 2018. A total of 260 copies of the survey was distributed, 250 of which were returned, with a response rate of $96.15 \%$. Out of the 250, one was not up to the quality of research, so 249 were used for research $(95.77 \%)$. The answers for each item ranged on a scale from 5 (yes, very) to 1 (not at all).

\subsubsection{MEASUREMENT TOOL FOR EQUIPMENT MAINTENANCE INFORMATION SYSTEM:}

The standards used to evaluate the quality of the equipment maintenance information system were divided into functional quality, OS quality, network quality, and content quality. Based on information assessment quality standards employed in past research [3, $6,8,9,13,14]$, the survey items were composed as follows.

Table I. Measurement Tool and Content

\begin{tabular}{c|c|l}
\hline Factor & $\begin{array}{c}\text { Number } \\
\text { of items }\end{array}$ & \multicolumn{1}{|c}{ Content } \\
\hline \hline $\begin{array}{c}\text { Functional } \\
\text { Quality }\end{array}$ & 3 & $\begin{array}{l}\text { Excellence of system's display resolution, response speed \& user } \\
\text { convenience }\end{array}$ \\
\hline $\begin{array}{c}\text { OS } \\
\text { Quality }\end{array}$ & 4 & $\begin{array}{l}\text { System's diversity of use with existing OS, System's synchronization and } \\
\text { convenience, System's ease of use, High applicability of OS }\end{array}$ \\
\hline $\begin{array}{c}\text { Network } \\
\text { Quality }\end{array}$ & 3 & $\begin{array}{l}\text { System's excellence of access speed, Easy access to information source, } \\
\text { Excellence of network }\end{array}$ \\
\hline $\begin{array}{c}\text { Content } \\
\text { Quality }\end{array}$ & 3 & $\begin{array}{l}\text { Meaningful content, Applicability of system's content, System's diversity of } \\
\text { content }\end{array}$ \\
\hline $\begin{array}{c}\text { Service } \\
\text { Quality }\end{array}$ & 3 & $\begin{array}{l}\text { System's excellence, Fast and good post-service awareness, Quickness of } \\
\text { the system }\end{array}$ \\
\hline
\end{tabular}


3.2.2. PERCEIVED EASE: Perceived ease [4] refers to whether the user can easily learn new information technologies and services when they are introduced, and it means that not much physical or mental effort is required in the process of using the technologies. In this study, perceived ease was defined as the degree of belief that it is easy to use the equipment maintenance information system of military units. The perceived ease was measured using a total of four items, as shown in Table II, referring to the items used in Davis [4] and Lee Bong-gyu et al. [10].

Table II. Perceived ease measurement tool and content

\begin{tabular}{ll}
\hline Factor $\begin{array}{c}\text { Number } \\
\text { of items }\end{array}$ & Content of items \\
\hline \hline & $\begin{array}{l}\text { Information retrieval using the equipment maintenance information system is } \\
\text { convenient. } \\
\text { With the equipment maintenance information system, information can be obtained } \\
\text { conveniently at any time. }\end{array}$ \\
$\begin{array}{c}\text { Perceived } \\
\text { ease }\end{array}$ & $\begin{array}{l}\text { The equipment maintenance information system can be easily used for information } \\
\text { acquisition. } \\
\text { The equipment maintenance information system can be used to get necessary } \\
\text { information at any time. }\end{array}$ \\
\hline
\end{tabular}

3.2.3. PERCEIVED USEFULNESS: Perceived usefulness [4] was said to be the degree to which using new technologies or certain systems is believed to bring about work productivity or efficiency beneficial to the user. In this study, it was defined as the degree to which the utilization value of the military unit's equipment maintenance information system is recognized as high. The perceived usefulness was measured using a total of four items, as shown in Table 3, referring to the items used in Davis [4] and Lee Bong-gyu et al., [10].

Table III. Perceived usefulness measurement tools and content

\begin{tabular}{|c|c|c|}
\hline Factor & $\begin{array}{l}\text { Number of } \\
\text { items }\end{array}$ & Content of items \\
\hline \multirow{4}{*}{$\begin{array}{l}\text { Perceived } \\
\text { usefulness }\end{array}$} & \multirow{4}{*}{4} & $\begin{array}{l}\text { The information obtained by using the equipment maintenance information system } \\
\text { is useful. }\end{array}$ \\
\hline & & $\begin{array}{l}\text { The use of the equipment maintenance information system for information } \\
\text { acquisition is valuable. }\end{array}$ \\
\hline & & $\begin{array}{l}\text { The use of the equipment maintenance information system for information } \\
\text { acquisition is effective. }\end{array}$ \\
\hline & & The equipment maintenance information system is essential to obtain information. \\
\hline
\end{tabular}

3.2.4. CONTINUOUS USE INTENTION: Continuous use intention can be defined as the user's behavioral intent to continue to use the equipment maintenance information system in the future. The degree of customer loyalty will depend on how satisfied equipment maintenance information system users are with the services provided to them, and on the basis of this, users' continuous use hereafter can be expected. The continuous use intention was measured using four items in total, as shown in Table 4, made by modifying and supplementing the items used in Shin Dong-hee and Kim Seong-jung [15], Cho Yu-je and Choi Jeong-il [2], and Wu and Wang [17]. 
Table IV. Continuous use intention measurement tool and content

\begin{tabular}{|c|c|c|}
\hline Factor & $\begin{array}{l}\text { Number of } \\
\text { items }\end{array}$ & Content of items \\
\hline \multirow{4}{*}{$\begin{array}{l}\text { Continuous } \\
\text { use } \\
\text { intention }\end{array}$} & \multirow{4}{*}{4} & I will use the equipment maintenance information system. \\
\hline & & I am willing to continue to use the equipment maintenance information system. \\
\hline & & $\begin{array}{l}\text { I am willing to recommend the use of the equipment maintenance information } \\
\text { system to others. }\end{array}$ \\
\hline & & I will continue to use the equipment maintenance information system. \\
\hline
\end{tabular}

\section{RESULTS OF EMPIRICAL ANALYSIS}

The measurement tools in this study were made by deriving questionnaire items based on previous studies, and the content validity of the measurement tools was secured. The explanatory factor analysis (EFA) of SPSS 22.0 and the confirmatory factor analysis (CFA) of AMOS 22.0 were conducted for data analysis and the significance level was set to $\mathrm{p}<.05$. First, frequency analysis and descriptive statistics were carried out to examine the general characteristics of the subjects of this survey. Second, EFA and CFA were conducted to verify the validity of the measurement tools in this study and Cronbach's alpha coefficients of reliability analysis were derived to verify the reliability of the measurement tools. Third, Pearson correlation analysis was conducted to examine the correlations between the measurement tools in this study. Fourth, to grasp detailed factors of military units' equipment maintenance information systems that affect perceived ease, perceived usefulness, and continuous use intention and structural relationships among individual variables, the equipment maintenance information system was set as an independent variable and a structural equation model was made.

\subsection{EXPLORATORY FACTOR ANALYSIS (EFA) AND RELIABILITY VERIFICATION}

The exploratory factor analysis was carried out by conducting principal component analyses by measurement tool using the varimax rotation method. Factors were extracted based on the condition that their eigenvalues were shown to be at least 1.0. In the process of carrying out the factor analysis, items with factor loading that shows values not higher than 0.5 , those with factor loading not lower than 0.5 belonging to two or more factors, those with the Cronbach's alpha coefficient lower than 0.6, and those with the item of each factor that cannot theoretically secure legitimacy were removed, as they were judged as lacking validity. The construct validity was secured by removing inappropriate items based on the criteria as such and the measurement items derived through the factor analysis were used as variables for hypothesis testing thereafter.

4.1.1. EQUIPMENT MAINTENANCE INFORMATION SYSTEM: Five factors were derived from the factor analysis and reliability analysis of the equipment maintenance information system, which was a variable used, and all of them had eigen values not lower than 1.0. These factors were named "operating system quality," "function quality," "content quality," "service quality," and "network quality." The KMO was shown to be 0.888 , thereby verifying the goodness of fit of the samples. Since approximated $-2233.709, p=0.000$ was shown when $\mathrm{df}=120$ and significance level $\alpha<0.05$, the unit matrices for the correlation matrix between the measurement items for the factor analysis were tested and the results indicated that the equipment maintenance information system measurement items were variables suitable for factor analysis. The total variance explanation power was shown to be $76.540 \%$, indicating that the variables in this study were well explained with five dimensions. All the factor loadings of individual 
measurement items derived from the five factors were shown to be at least 0.5 , so that the measurement items in the results of the factor analysis for the equipment maintenance information system secured validity. The reliability (Cronbach's $\alpha$ ) value of the factor "operating system quality" was shown as 0.876 , that of the factor "function quality" as 0.862 , that of the factor "content quality" as 0.849 , that of the factor "service quality" as 0.813 , and that of the factor "network quality" as 0.842 . Therefore, the reliability values of all factors were shown to be higher than the reference value, 0.6. Therefore, in the factor analysis for the equipment maintenance information system in this study, the internal consistency of all factors was verified.

4.1.2. PERCEIVED EASE AND PERCEIVED USEFULNESS: In the factor analysis and reliability analysis for the variables perceived ease and perceived usefulness, two factors with eigen values not lower than 1.0 were derived. The factors were named "perceived ease" and "perceived usefulness." The KMO was shown to be 0.853 , thereby verifying the goodness of fit of the samples. Since approximated $-1224.115, \mathrm{p}=0.000$ was shown when $\mathrm{df}=120$ and significance level $\alpha<0.05$, the unit matrices for the correlation matrix between the measurement items for the factor analysis were tested and the results indicated that the perceived ease and perceived usefulness measurement items were variables suitable for factor analysis. The total variance explanation power was shown to be $72.767 \%$, indicating that the variables in this study were well explained with two dimensions. All the factor loadings of individual measurement items derived from the two factors were shown to be at least 0.5 , so that the measurement items in the results of the factor analysis for perceived ease and perceived usefulness secured validity. The reliability (Cronbach's $\alpha$ ) value of the factor "perceived ease" was shown as 0.893 and that of the factor "perceived usefulness" was shown as 0.838 . Therefore, the reliability values of all factors were shown to be higher than the reference value, 0.6. Therefore, in the factor analysis for perceived ease and perceived usefulness in this study, the internal consistency of all factors was verified.

4.1.3. CONTINUOUS USE INTENTION: In the factor analysis and reliability analysis for the variable continuous use intention, one factor with the eigen value not lower than 1.0 was derived. The factor was named "continuous use intention." The KMO was shown to be 0.813 , thereby verifying the goodness of fit of the samples. Since approximated- $=601.154, \mathrm{p}=0.000$ was shown when $\mathrm{df}=6$ and significance level $\alpha<0.05$, the unit matrices for the correlation matrix between the measurement items for the factor analysis were tested and the results indicated that the continuous use intention measurement items were variables suitable for factor analysis. The total variance explanation power was shown to be $76.169 \%$, indicating that the variables in this study were well explained with a single dimension. All the factor loadings of individual measurement items derived from the two factors were shown to be at least 0.5 , so that the measurement items in the results of the factor analysis for continuous use intention secured validity. The reliability (Cronbach's $\alpha$ ) value of the factor "continuous use intention" was shown as 0.895 . Therefore, the reliability value was shown to be higher than the reference value, 0.6.

\subsection{CONFIRMATORY FACTOR ANALYSIS (CFA)}

The fit indices for the measurement model of the equipment maintenance information system, perceived ease, perceived usefulness, and continuous use intention, the configuration variables in this study, were shown to be $\mathrm{X} 2=607.52(\mathrm{p}=.000, \mathrm{df}=318$ ), GFI $=.848, \quad \mathrm{CFI}=.937, \quad \mathrm{NFI}=.877, \quad \mathrm{IFI}=.937, \quad \mathrm{RFI}=.854, \quad \mathrm{TLI}=.925, \quad \mathrm{RMR}=.042$, RMSEA=.061. Mulaik et al. (1989) judged that the values of GFI, CFI, and NFI were good when they were at least 0.8-0.9, and Steiger and Lind (1980) judged that RMR was 
good when it did not exceed 0.05 and RMSEA was good when it did not exceed 0.08 . Since all the goodness of fit indices in the confirmatory factor analysis in this study are within the range of the reference values mentioned earlier or shown to be better, the goodness of fit of the model used in this study is judged to be very good. In addition, according to the results of confirmatory factor analysis, the factor loading values of individual items of all factors were shown to be at least 0.50 and all $t$-values were shown to be not lower than the reference value $1.965(\mathrm{p}<.05)$, thereby indicating that the values for all factors were significant.

\subsection{DESCRIPTIVE STATISTICS AND CORRELATION ANALYSIS OF MAJOR VARIABLES}

The descriptive statistics of sub areas of the equipment maintenance information system, perceived ease, perceived usefulness, and continuous use intention, major variables in this study, were analyzed and according to the results, the mean of the scores of service quality under the equipment maintenance information system was at the highest level with a value of 3.84 , followed by network quality with a mean value of 3.76 , operating system quality with a mean value of 3.34 , content quality with a mean value of 3.15 , and function quality with a mean value of 2.84 . In addition, it could be seen that perceived ease $(\mathrm{M}=3.15, \mathrm{SD}=.765)$, perceived usefulness $(\mathrm{M}=3.31, \mathrm{SD}=.844)$, and continuous use intention $(\mathrm{M}=3.38, \mathrm{SD}=.802)$ were all evaluated to be at about the middle level. In addition, Pearson correlation analysis, which is used most commonly, was conducted to analyze the correlations between the equipment maintenance information system, perceived ease, perceived usefulness, and continuous use intention and the results indicated that the correlation coefficients between the variables were in a range of 0.2720.662 . In correlation analyses, when the correlation coefficient between two variables has a value not lower than 0.90 , the two variables are regarded to be almost the same and the problem of multicollinearity occurs. According to the results of the correlation analysis in this study, it was judged that no variable caused the problem of multicollinearity. Therefore, since the correlation coefficients between individual variables were statistically significant and their values were smaller than 0.9 , the discriminant validity was secured.

\section{HYPOTHESIS TESTING}

\subsection{STUDY MODEL TESTING}

The model was analyzed using AMOS for hypothesis testing. The covariance matrix was used for the analysis of the study model and maximum likelihood estimation (MLE) was used for the structural equation model. The goodness of fit of the study model appeared as shown in Table V, thereby showing good reference values.

Table V. Goodness of fit of the study model for the study hypotheses

\begin{tabular}{c|c|c|c|c|c|c|c|c}
\hline $\boldsymbol{X}^{2}(\boldsymbol{p})$ & $\boldsymbol{d} \boldsymbol{f}$ & GFI & CFI & NFI & IFI & TLI & RMR & RMSEA \\
\hline \hline $\begin{array}{c}668.425 \\
(p=0.000)\end{array}$ & 324 & .834 & .925 & .865 & .925 & .912 & .051 & .065 \\
\hline
\end{tabular}

The hypotheses in this study were tested by checking the path coefficients. In addition, there are differences in testing between cases where directivity $(+,-)$ is presented and cases where no directivity is presented. Directivity is not presented in study hypotheses [11] in cases where the direction of effects cannot be set forth based on theoretical reasoning or extensive observation. However, in cases where the direction of effects can be set forth as "positive (+)" based on theoretical reasoning or extensive observation, the 
content regarding the directivity should be included in the study hypotheses tested by one-tailed tests. When the structural equation was analyzed, as shown in Table VI, operating system quality, network quality, content quality, and service quality, which are subfactors under the equipment maintenance information system, were shown to affect perceived ease, and function quality, operating system quality, content quality, and service quality under the equipment maintenance information system and perceived ease was shown to affect perceived usefulness. Perceived ease and perceived usefulness were shown to affect continuous use intention.

Table VI. Results of Structural Equation Analysis

\begin{tabular}{|c|c|c|c|c|c|c|c|}
\hline Hypothesis & & Path & & $\begin{array}{c}\text { Standardized } \\
\text { coefficient }\end{array}$ & SD & $t$ & $p$ \\
\hline H1-1 & Function quality & $\rightarrow$ & \multirow{5}{*}{ Perceived ease } & 0.103 & 0.061 & 1.470 & 0.142 \\
\hline H1-2 & $\begin{array}{c}\text { Operating system } \\
\text { quality }\end{array}$ & $\rightarrow$ & & 0.211 & 0.079 & $2.286^{*}$ & 0.022 \\
\hline $\mathrm{H} 1-3$ & Network quality & $\rightarrow$ & & 0.308 & 0.094 & $3.062^{* * *}$ & 0.002 \\
\hline $\mathrm{H} 1-4$ & Content quality & $\rightarrow$ & & 0.427 & 0.072 & $4.772^{* * *}$ & 0.000 \\
\hline $\mathrm{H} 1-5$ & Service quality & $\rightarrow$ & & 0.517 & 0.086 & $5.220^{* * * *}$ & 0.000 \\
\hline $\mathrm{H} 2-1$ & Function quality & $\rightarrow$ & \multirow{5}{*}{$\begin{array}{l}\text { Perceived } \\
\text { usefulness }\end{array}$} & 0.160 & 0.064 & $2.657^{* * *}$ & 0.008 \\
\hline $\mathrm{H} 2-2$ & $\begin{array}{c}\text { Operating system } \\
\text { quality }\end{array}$ & $\rightarrow$ & & 0.241 & 0.086 & $2.951^{* *}$ & 0.003 \\
\hline $\mathrm{H} 2-3$ & Network quality & $\rightarrow$ & & 0.096 & 0.105 & 1.046 & 0.296 \\
\hline $\mathrm{H} 2-4$ & Content quality & $\rightarrow$ & & 0.291 & 0.085 & $3.376^{* * * *}$ & 0.000 \\
\hline $\mathrm{H} 2-5$ & Service quality & $\rightarrow$ & & 0.219 & 0.105 & $2.214^{*}$ & 0.027 \\
\hline $\mathrm{H} 3$ & Perceived ease & $\rightarrow$ & $\begin{array}{l}\text { Perceived } \\
\text { usefulness }\end{array}$ & 0.500 & 0.140 & $4.369^{* * *}$ & 0.000 \\
\hline $\mathrm{H} 4$ & Perceived ease & $\rightarrow$ & \multirow{2}{*}{$\begin{array}{l}\text { Continuous use } \\
\text { intention }\end{array}$} & 0.324 & 0.108 & $2.927^{* * *}$ & 0.003 \\
\hline H5 & $\begin{array}{l}\text { Perceived } \\
\text { usefulness }\end{array}$ & $\rightarrow$ & & 0.494 & 0.087 & $4.507^{* * *}$ & 0.000 \\
\hline
\end{tabular}

${ }^{* * * *} p<.001,{ }^{* * *} p<.01,{ }^{*} p<.05$

\subsection{TESTS OF DIRECT AND INDIRECT EFFECTS, TOTAL EFFECTS}

Using the structural equation model, the indirect effects and total effects of the measurement variables in this study can be derived. Indirect effects [1] are the effects of independent variables on dependent variables further strengthened by one or more parameters inputted in the middle of the relationship between independent variables and dependent variables and are obtained by multiplying the standardized estimated values of the parameters by each other. The total effects are values obtained by adding up direct effect values and indirect effect values. When there is no indirect effect, the direct effect value indicates the total effect value. Therefore, the indirect effects on perceived ease and perceived usefulness are as shown in Table 7 and Table 8 . That is, paths with indirect effects on perceived ease in the relationships between operating system quality, network quality, content quality, and service quality under the equipment maintenance information system and perceived usefulness paths with indirect effects on perceived ease were shown to have significant indirect effects on all paths at the level of $\mathrm{p}<.05$, and in the relationships between the equipment maintenance information system and perceived ease/continuous use intention, paths with indirect effects on perceived usefulness were shown to have significant indirect effects on all paths at the level of $\mathrm{p}<.05$. 
Table VII. Tests of the indirect effects of perceived ease

\begin{tabular}{|c|c|c|c|c|c|c|c|c|c|}
\hline Hypothesis & & ath & & $\begin{array}{c}\text { Direct } \\
\text { effect }\end{array}$ & $p$ & $\begin{array}{c}\text { Indirect } \\
\text { effect }\end{array}$ & $p$ & $\begin{array}{l}\text { Total } \\
\text { effect }\end{array}$ & $p$ \\
\hline \multirow{5}{*}{ H6 } & Function quality & $\rightarrow$ & \multirow{5}{*}{$\begin{array}{l}\text { perceived } \\
\text { usefulness }\end{array}$} & $.160^{* *}$ & .008 & .052 & .189 & $.212^{* *}$ & .002 \\
\hline & $\begin{array}{l}\text { Operating } \\
\text { system } \\
\text { quality }\end{array}$ & $\rightarrow$ & & $.241^{* *}$ & .003 & $.105^{*}$ & .049 & $.346^{* * *}$ & .000 \\
\hline & $\begin{array}{l}\text { Network } \\
\text { quality }\end{array}$ & $\rightarrow$ & & .096 & .296 & $.154^{* *}$ & .006 & $.250^{* * * *}$ & .000 \\
\hline & Content quality & $\rightarrow$ & & $.291^{* * *}$ & .000 & $.213^{* *}$ & .008 & $.504^{* * *}$ & .000 \\
\hline & Service quality & $\rightarrow$ & & $.219^{*}$ & .027 & $.258^{* *}$ & .005 & $.477^{* * * *}$ & .000 \\
\hline
\end{tabular}

${ }^{* * * *} p<.001,{ }^{* *} p<.01,{ }^{*} p<.05$

Table VIII. Tests of the indirect effects of perceived usefulness

\begin{tabular}{cccccccc}
\hline Hypothesis & Path & $\begin{array}{c}\text { Direct } \\
\text { effect }\end{array}$ & $\boldsymbol{p}$ & $\begin{array}{c}\text { Indirect } \\
\text { effect }\end{array}$ & $\boldsymbol{p}$ & $\begin{array}{c}\text { Total } \\
\text { effect }\end{array}$ & $\boldsymbol{p}$ \\
\hline \hline $\mathrm{H} 7 \quad$ perceived ease $\rightarrow$ & $\begin{array}{c}\text { continuous } \\
\text { use intention }\end{array}$ & $.324^{* *}$ & .003 & $.247^{* *}$ & .004 & $.571^{* * *}$ & .000 \\
\hline
\end{tabular}

${ }^{* * * *} p<.001,{ }^{* * *} p<.01,{ }^{*} p<.05$

\section{EQUIPMENT MAINTENANCE INFORMATION SYSTEM IMPROVEMENT PLAN}

Questionnaire surveys were conducted on the function quality, operating system quality, network quality, content quality, and service quality of the equipment maintenance information system to identify the shortcomings of the current system, and according to the results, it could be seen that function quality had relatively low average scores, as shown in Table IX, and that the reason was very low actual senses of use in the system part of the equipment maintenance information system. This is because, despite that the weapon systems are quite diverse and there are diverse histories of repairs depending on weapon systems, the level of the current system per se is very low.

Table IX. Results of measurement of the equipment maintenance information system by quality $(\mathrm{N}=249)$

\begin{tabular}{cccccc}
\hline & $\begin{array}{c}\text { Function } \\
\text { quality }\end{array}$ & $\begin{array}{c}\text { Operating } \\
\text { system quality }\end{array}$ & $\begin{array}{c}\text { Network } \\
\text { quality }\end{array}$ & $\begin{array}{c}\text { Content } \\
\text { quality }\end{array}$ & $\begin{array}{c}\text { Service } \\
\text { quality }\end{array}$ \\
\hline \hline Mean (M) & 2.84 & 3.34 & 3.76 & 3.15 & 3.84 \\
\hline $\begin{array}{c}\text { Standard } \\
\text { deviation (SD) }\end{array}$ & .909 & .807 & .718 & .814 & .709 \\
\hline
\end{tabular}

Therefore, grounds for a proposed improvement model will be prepared by using the factors checking for vulnerabilities of function quality among the vulnerabilities of the equipment maintenance information system derived as shown in the results of analysis set forth in Sections 4 and 5. Also, since the South Korean military actually has an insufficient understanding of the equipment maintenance information system and insufficient awareness of the necessity of the system, we propose the improvement model to first provide an index for quality improvement. In addition, rather than approaching all processes at once, implementing one to three quality processes simultaneously is judged reasonable. Therefore, it is proposed to first introduce the service desk process, which is most important to provide the best service to users of the equipment maintenance 
information system, followed by system management and improvement processes, and gradually introduce other processes periodically to achieve improvement and development of the processes. For this improvement, we propose an index of priorities of qualities for the introduction of processes for the equipment maintenance information system based on the average data values calculated by item of the equipment maintenance information system. The priorities by quality are selected beginning with the quality with the lowest score in the direction toward quality improvement in order to introduce the life cycle of the equipment maintenance information system. When the characteristics of the South Korean military are considered and a greater weight is placed on the aspect of user service improvement, the priorities can be given as shown in Table X. In order to introduce an improved equipment maintenance information system, approaches based on the priorities derived from the life cycle are required, and the relevant requirements should be appropriately derived to fit the priorities.

Table X. Priorities for introduction of the life cycle using the equipment maintenance information system quality index

\begin{tabular}{|c|c|c|}
\hline Priorities & $\begin{array}{l}\text { Elements to be } \\
\text { checked }\end{array}$ & Detailed description \\
\hline \multirow{3}{*}{1} & System use convenience & Convenience of use of the equipment maintenance information system \\
\hline & System response speed & Response speed of the equipment maintenance information system \\
\hline & System picture quality & $\begin{array}{l}\text { Degree of comfort and clearness of the picture quality of the } \\
\text { equipment maintenance information system }\end{array}$ \\
\hline \multirow{3}{*}{2} & Content usability & $\begin{array}{l}\text { Degree of utilization of the content of the equipment maintenance } \\
\text { information system in business practice }\end{array}$ \\
\hline & Content playfulness & $\begin{array}{l}\text { Degree of interest in the content of the equipment maintenance } \\
\text { information system }\end{array}$ \\
\hline & Content diversity & $\begin{array}{l}\text { Kinds of contents of the equipment maintenance information system } \\
\text { in relation to the suitability of the system for use in business practice }\end{array}$ \\
\hline \multirow{3}{*}{3} & Synchronization & $\begin{array}{c}\text { Degree of synchronization of the equipment maintenance information } \\
\text { system before and after use of the system }\end{array}$ \\
\hline & Ease of use and suitability & $\begin{array}{l}\text { Difficulty of use of the equipment maintenance information system } \\
\text { and the system's suitability for business practice }\end{array}$ \\
\hline & $\begin{array}{l}\text { Compatibility with } \\
\text { existing operating } \\
\text { systems and variety }\end{array}$ & $\begin{array}{l}\text { Compatibility with existing operating systems of the equipment } \\
\text { maintenance information system after its update }\end{array}$ \\
\hline \multirow{3}{*}{4} & Easy access to the system & $\begin{array}{l}\text { Degree of difficulty of access to the equipment maintenance } \\
\text { information system for use }\end{array}$ \\
\hline & $\begin{array}{l}\text { Excellence of access } \\
\text { speed }\end{array}$ & $\begin{array}{l}\text { Degree of time taken to access the equipment maintenance } \\
\text { information system for use }\end{array}$ \\
\hline & Excellence of the network & $\begin{array}{l}\text { Degree of smoothness of networking with computer networks } \\
\text { connected to the equipment maintenance information system for use }\end{array}$ \\
\hline \multirow{3}{*}{5} & System excellence & Overall excellence of the equipment maintenance information system \\
\hline & System speed & Overall speed of the equipment maintenance information system \\
\hline & A/S management & $\begin{array}{l}\text { Overall management of } \mathrm{A} / \mathrm{S} \text { of the equipment maintenance } \\
\text { information system }\end{array}$ \\
\hline
\end{tabular}

In addition, since the factors of the equipment maintenance information system were shown to statistically significantly affect continuous use intention in this study through the analysis of the technology acceptance model, the following direction of improvement is presented.

First, the findings of this study can be analyzed as indicating that although the equipment maintenance information system has been well established, its efficiency in relation to actual jobs is low. Based on these findings, the program of the military 
equipment maintenance information system should be improved by accepting its vulnerability in relation to users and considering convenience and job efficiency from the viewpoint of users, or measures in relation to effective education, including the infrastructure of the equipment maintenance information system, should be prepared. Despite that the equipment maintenance information system has been well established, if it is used by users without sufficient job knowledge, there may be difficulties in system operation. The use of the equipment maintenance information system should be promoted for continuous development of the system, and because of the nature of the military, superiors and commanders including the practitioners should themselves actively encourage the use of the system. In addition, the use of system should be promoted by inducing the performance of munitions work through military unit evaluation, etc.

Second, most of the actual persons in charge of the equipment maintenance information system are low-ranking noncommissioned officers, and they carry out their work without completing specialized education for munitions. In order to improve and utilize the system, efforts should be made to increase their confidence in work and expertise in their jobs in the larger framework of munitions work. That is, using the technology acceptance model, important factors were proposed for the recognition of the present situation of the equipment maintenance information system and for the improvement and development of the system in terms of practice.

Academically, this study can be meaningful in that it studied factors influencing continuous use intention in the field of the equipment maintenance information system that uses multiple technologies by applying the technology acceptance model (TAM) for the first time.

\section{CONCLUSION}

This study examined the effects of the use factors of the equipment maintenance information system, which is a military information system, on the continuous use intention based on perceived ease and perceived usefulness using the technology acceptance model in the special organization termed the military and presented measures to promote the intention to continuously use the system. To that end, hypotheses regarding the effects on continuous use intention were set up centering on users belonging to the special organization termed the military and the hypotheses were tested. The results are as follows.

First, among the function quality, operating system quality, network quality, content quality, and service quality classified into subfactors of the equipment maintenance information system, function quality was shown to have the lowest mean score, followed by content quality, operating system quality, service quality, and network quality, in order of precedence. This indicates that among the qualitative elements of the equipment maintenance information system, picture quality, response speed, and user convenience, which are function qualities, are vulnerable. These results are important in that they tell what the vulnerabilities are in the present situation of the equipment maintenance information system, and when seen from another angle they can be interpreted as indicating that the system cannot but be passively used to maintain jobs. Even if the equipment maintenance information system has been well established, if sufficient user convenience is not provided, the difficulty of the system will remain and the willingness to use it continuously will be reduced. The service quality of the equipment maintenance information system, which was shown to have the highest mean score, can be interpreted as indicating the excellence of the system, fast and smooth $\mathrm{A} / \mathrm{S}$, and high speed of use. These conditions are important ones that can be directly related to the efficiency of practical work, and given the work related to the system and other environmental variables, efficient performance is expected hereafter. The perceived ease and usefulness of the equipment maintenance information system were shown to have slightly higher 
scores than their respective mean scores, indicating that the efficiency of the system is still insufficient. The continuous use intention for the equipment maintenance information system in relation to military jobs was also shown to have a score slightly higher than the average.

Second, among the factors of the equipment maintenance information system affecting perceived ease, service quality was shown to have the largest effect, followed by content quality, network quality, and operating system quality, in order of precedence. Next, among the factors affecting perceived usefulness, content quality was shown to have the largest effect, followed by operating system quality, service quality, and function quality, in order of precedence. In addition, it could be seen that perceived ease significantly affects perceived usefulness. Among the factors that affect continuous use intention, perceived usefulness was shown to have the largest effect, followed by perceived ease. Among the paths that affect perceived ease in the relationships between the factors of the equipment maintenance information system and perceived usefulness, the path [service quality-perceived ease-perceived usefulness] was shown to have the largest effect, followed by [content quality-perceived ease-perceived usefulness], [network qualityperceived ease-perceived usefulness], and [operating system quality-perceived easeperceived usefulness] in order of precedence. In addition, it could be seen that perceived usefulness showed significant indirect effects in the relationship of [perceived easeperceived usefulness-continuous use intention].

Based on the statistical findings indicating that functional quality does not significantly affect perceived ease in fact, it can be seen that the equipment maintenance information system has poor functional convenience and its efficiency in the retrieval of related data and utilization of related data through networks is actually low. On the other hand, the system is considered useful in terms of the convenience of jobs with the excellence and speed of the system per se and the diversity and usability of functions. That is, among the vulnerabilities that must be complemented, the functional elements of the equipment maintenance information system considering user convenience and the speed of the system network were shown to be important factors that must be improved, while the excellence of the system per se and the possibility of various uses of the system can be regarded as elements for continuous use of the system.

\section{ACKNOWLEDGMENTS}

This study was partially supported by the Research Fund of Howon University, Korea.

\section{REFERENCES}

[1] Bae Byeog-ryeo, "Structural Equation Modeling of structural equation (by Amos7): Principles and practice", Cheongram, (2007).

[2] Cho Yu-je and Choi Jeong-il. "A Study on the Effect of Perceived Characteristics of Smartphone Application Users on Continuous Use Intention", Journal of Korea IT Services Society, vol. 10, (2011): 41-60.

[3] Choi Se-Keum, Kim Young-min and Lee Jae-chon, "Determination of Key Elements Using FTA/FMEA Safety Techniques for Precedent Research Stage of Defense R\&D Programs", Journal of the Korea Academia-Industrial cooperation Society, Vol. 19, No. 9 (2018): 50-61.

[4] Davis, "Perceived usefulness, perceived ease of use, and user acceptance of information technology", MIS quarterly, (1989), 319-340.

[5] Davis, Fred D., Richard P. Bagozzi, and Paul R. Warshaw, "User acceptance of computer technology: a comparison of two theoretical models", Management science, Vol. 35, No. 8 (1989): 982-1003.

[6] Ketola, Pekka, and Mika Röykkee, "The three facets of usability in mobile handsets", CHI 2001 Workshop: Mobile Communications: Understanding Users, Adoption \& Design, (2001).

[7] Kim Hak-joon and Jeon Soon-cheon, "Study of the Acceptance of Interested Parties (Auditor /Auditee) in the Information System Audit Technologies Based Technology Acceptance Model(TAM)", Journal of the Korea Academia-Industrial cooperation Society, Vol. 16, No. 2 (2015): 1403-1413.

[8] Kim Ji-hun, "A Study on the Intention to Accept Smartphones: Focusing on the Spread of the TAM Model”, Master's Thesis, Konkuk University, (2010). 
[9] Kwon Yeong-jae and Cheon Dong-eun, "Comparative Analysis and Direction of Development of Smartphone Operating Systems", Telecommunication review, Vol. 21, No. 2, (2011): 242-250.

[10] Lee Bong-gyu, Kim Ki-yeon, and Lee Hye-seon, "An Analysis of the Effects of Playfulness and Economic Variables on Mobile Advertising Value and Access Intention", Journal of Korea Information Processing Society. Vol. 16, No. 1 (2009): 43-54.

[11] Lee Hak-Sik and Lim Ji-hun, "Structural Equation Model and AMOS 16.0", Bopmunsa, (2007).

[12] Lee Jeong-seop and Jang S-yeong, "Expansion of the Technology Acceptance Model and User's Acceptance of Information Systems", Journal of Business Administration Research, Vol. 32, No. 5 (2003), pp. 1415-1451.

[13] Meadow, Charles T., and Weijing Yuan, "Measuring the impact of information: defining the concepts", Information Processing \& Management, Vol. 33, No. 6, (1997), 697-714.

[14] Shim Jae-sung, Yun Sung-yeol and Park Seok-cheon, "A Study on Wireless Data Quality Measurement Method for u-Healthcare Service in WiBro Environment", Journal of the Korea Academia-Industrial cooperation Society, vol. 13, no. 2, (2012), pp. 843-841.

[15] Shin Dong-hee and Kim Seong-jung, "A Study on the Continuous Use of Smartphone Using the Expectation-Satisfaction Model”, Korean Journal of Journalism \& Communication Studies, vol. 56, no. 2, (2012), pp. 331-356.

[16] Venkatesh, Viswanath, and Susan A. Brown, "A longitudinal investigation of personal computers in homes: adoption determinants and emerging challenges", MIS quarterly, (2001), pp. 71-102.

[17] Wu, Jen-Her and Shu-Ching Wang, "What drives mobile commerce: An empirical evaluation of the revised technology acceptance model", Information \& management, Vol. 42, No. 5 (2005), pp. 719-729.

[18] You Jae-hyun and Park Cheol, "A Comprehensive Review of the Technology Acceptance Model", Entrue Journal of Information Technology, Vol. 9, No. 2 (2010): 31-50. 